\title{
Between 7 and 8.5 Hours
}

National Cancer Institute

\section{Source}

National Cancer Institute. Between 7 and 8.5 Hours. NCI Thesaurus. Code C156950.

An indication that something has lasted, occurred during, or totalled between 7 and 8.5 hours. 